\title{
Pesquisas de clima e endomarketing para pequenas empresas
}

\author{
RESUMO
}

Barbara Welter de Abreu barbara.dwelter@gmail.com Universidade Federal de Santa Catarin (UFSC), Florianópolis, Santa Catarina, Brasil

Caroline Rodrigues Vaz caroline.vaz@posgrad.ufsc.br Universidade Federal de Santa Catarina (UFSC), Florianópolis, Santa Catarina, Brasil

Mauricio Uriona Maldonado

\section{m.uriona@ufsc.br}

Universidade Federal de Santa Catarina (UFSC), Florianópolis, Santa Catarina, Brasil
Este artigo teve como objetivo desenvolver uma estratégia de endomarketing para pequenas empresas do setor imobiliário. A pesquisa se caracteriza como exploratóriodescritiva, através da pesquisa-ação, com utilização de um questionário estruturado adaptado do modelo de clima organizacional de Luz (2003). Os resultados apresentados nesta pesquisa foram considerados adequados e de grande valia para área imobiliária, pois permitiu medir o clima organizacional da empresa investigada. A pesquisa permitiu medir os fatores internos da empresa e não os externos, como problemas familiares. Nesta pesquisa foi possível diagnosticar os fatores críticos através do índice de favorabilidade e pelo índice potencial de melhoria. Desta maneira, a priorização da empresa está em adotar ações de implantação no plano de carreiras e a caixa de sugestões. O endomarketing usado foi desenvolvido para melhorar a motivação dos funcionários e melhorar os indicadores identificados como negativos pela pesquisa de clima organizacional.

PALAVRAS-CHAVE: Clima Organizacional. Pequenas Empresas. Endomarketing. Marketing Interno. 


\section{INTRODUÇÃO}

O estudo da motivação no trabalho possui um grande interesse por parte da literatura acadêmica e de mercado, por causa de sua relação próxima com o aumento ou diminuição da produtividade do indivíduo ou da organização (TAMAYO; PASCHOAL, 2003). Portanto, a problemática da motivação no ambiente de trabalho encontra-se na interseção entre os interesses da organização com os interesses do colaborador (TAMAYO; PASCHOAL, 2003), já que as organizações não conseguem funcionar se seus colaboradores não estiverem comprometidos em certo nível (STONER e FREEMAN, 1999).

Sendo assim, é importante conseguir medir até que ponto os colaboradores de uma empresa estão motivados, para que se possam tomar ações corretivas e preventivas com relação ao nível encontrado (LUZ et al., 2007). Contudo, de acordo com Luz (2007), essa mensuração apresenta vários desafios. Uma das maneiras para se medir a motivação é através das pesquisas de clima organizacional. Esta tem como objetivo apresentar aos líderes das empresas os níveis de motivação e satisfação de seu funcionário (LUZ et al., 2007).

O setor imobiliário é composto principalmente por pequenas empresas, muitas delas familiares, onde a alta rotatividade é uma característica permanente, pois a principal mão de obra são corretores de imóveis autônomos, com remuneração totalmente baseada em comissões. Além disso, existe alta incerteza de estabilidade laboral, pois a maioria dos corretores trabalham por contratos, que podem ser anulados a qualquer momento.

Assim, a falta de ações relacionadas com o acompanhamento da motivação dos colaboradores, aliada com os baixos recursos financeiros que as empresas de pequeno porte possuem para investimentos em programas de retenção de funcionários, faz com que o pequeno tempo de permanência dos mesmos dentro da empresa se torne um problema para essas organizações. Logo, existe um problema com relação ao aumento de produtividade nas vendas e a alta rotatividade dos funcionários, que é oriundo da falta de motivação dos mesmos.

Desta forma, define-se o problema de pesquisa: como utilizar as pesquisas de clima organizacional, em pequenas empresas do setor imobiliário, para buscar a melhoria da motivação dos colaboradores?

Para responder este problema de pesquisa, este artigo tem como objetivo desenvolver uma estratégia de endomarketing para pequenas empresas do setor imobiliário. Pois, não existe fórmula para que uma organização consiga aumentar a motivação dos empregados, ela só consegue estimulá-los de duas formas: integração e informação (BRUM, 2005). Brum (2010) afirma que o endomarketing é o melhor caminho para espalhar as informações de comprometimento e envolvimento dos colaboradores da organização.

O endomarketing tem como objetivo transformar os colaboradores no público principal da empresa e para isso, é preciso que exista uma sinergia entre a organização e as necessidades dos funcionários (BRUM, 2005; 2010). Desse modo, é possível atingir um clima mais equilibrado, gerando colaboradores mais motivados e satisfeitos, tendo como resultado uma maior produtividade (BRUM, $2005 ; 2010)$. 


\section{REFERENCIAL TEÓRICO}

\section{CLIMA ORGANIZACIONAL}

O conceito clima organizacional se refere aos aspectos motivacionais do ambiente, ou seja, as particularidades do ambiente que levam ao estímulo de diferentes tipos de motivação (CHIAVENATO, 2006).

Moran e Volkwein (1992) definem o clima organizacional como uma característica de uma empresa que possui uma duração relativamente longa e que contém as sensações coletivas dos colaboradores sobre a empresa com relação a diferentes aspectos como inovação, apoio, autonomia, honestidade, confiança etc. $O$ clima é gerado através dessas percepções e das interações entre os membros da empresa.

Silva (2001) aponta o clima organizacional como uma propriedade básica alterável e flexível. Logo, consegue ser mudado através das políticas e ações gerenciais. Lacombe (2005), por sua vez, relata que o termo é um reflexo do grau de satisfação pessoal de uma pessoa em relação ao ambiente de trabalho da organização, o mesmo está vinculado à confiança, motivação, grupo de trabalho, identificação da empresa, reconhecimento, comunicação interna acessível, colegas de trabalho, emoções e sentimentos, interesse no trabalho e outras variáveis.

Nesta linha, foram desenvolvidos instrumentos de pesquisa para avaliar o clima interno das organizações. Bedani (2006) conceitua a pesquisa de clima organizacional como um "mapeamento de percepções sobre o ambiente interno da organização" sendo ela um início para que aconteçam mudanças e crescimento na empresa. Luz (2001) complementa dizendo que ela pode ser considerada como um instrumento, que ao ser usado através de uma metodologia assertiva, consegue dar credibilidade as mudanças das empresas que buscam qualidade, eficácia e eficiência.

A pesquisa de clima é um instrumento importante para dar suporte ao processo de evolução constante da empresa (LUZ, 2003).

A seguir, serão apresentados quatro (4) modelos de pesquisas de clima organizacional, levantados da literatura, sendo eles:

O primeiro modelo é o de Litwin e Stringer (1968), que criaram uma pesquisa fundamentada em nove fatores. $\mathrm{O}$ segundo modelo de Kolb, (Kolb, 1986 apud Bispo, 2006) utiliza três indicadores de Litwin e Stringer (1968): responsabilidade, padrões e recompensas. Além desses três fatores, ele usa quatro outros elementos. O terceiro é o modelo de Sbragia (1983), que é composto por vinte indicadores, sete deles já foram explicados anteriormente: conformidade, estrutura, recompensas, cooperação, padrões, conflitos e identidade. E o quarto modelo é flexível e foi desenvolvido pelo autor Luz (2003), no qual a pessoa que irá aplicar a pesquisa poderá escolher entre as 172 perguntas propostas, as mais relevantes para o seu tipo de empresa. Em suas pesquisas o autor identificou diferentes variáveis, nas quais se baseou para construir o seu modelo, porém, ele classificou suas perguntas em apenas dois grandes grupos: Ambiente de Trabalho e Benefícios. No entanto, as perguntas 
que ele propõe abrangem muitos dos itens levantados já abordados pelos outros autores, sendo um questionário mais amplo.

\section{ENDOMARKETING}

O endomarketing surgiu a partir dos princípios que formam o marketing, com as características de os clientes internos serem considerados os primeiros clientes das empresas. Dessa forma, o endomarketing engloba os processos de criação do valor da empresa que devem ser percebidos pelos funcionários, devendo conter comprometimento, que demanda o engajamento aos objetivos e valores da organização, retenção de pessoas e oportunidades de crescimento profissional dentro da organização (BEKIN, 1995).

Com relação às ferramentas de endomarketing, Kunsch (2003) esclarece que em uma campanha de ações de endomarketing pode-se utilizar ferramentas como: boletins, murais, rádio, terminais de computador, caixa de sugestões, rádio, intranet, teatro etc.

A caixa de sugestões, por exemplo, é uma ação de fácil aplicação e traz resultados rápidos. Ela contribui para as melhorias da empresa e cria um canal de comunicação direto entre líderes da empresa e seus funcionários. Ademais, a caixa de sugestões mostra que a empresa quer se aproximar dos funcionários. $O$ estímulo é transformado em uma interação maior (FREIRE, 2009).

O plano de carreiras também é considerado como uma ferramenta de endomarketing, pois está inserido dentro da perspectiva de crescimento dos colaboradores. Este funciona como uma forma de incentivo aos trabalhadores da empresa, pois mostra que a organização valoriza o talento de seus funcionários, esta ferramenta é também uma maneira de evitar a rotatividade dentro da empresa (BEKIN, 2005).

No entanto, na literatura encontra-se outra forma de conceituar o endomarketing: o marketing interno. Para Azedo (2004), os termos podem ser diferentes, mas possuem um mesmo significado: conjunto de práticas e ideias de uma empresa que tem como propósito aumentar a motivação, o comprometimento e o desempenho dos colaboradores, repercutindo também nos clientes externos.

No entanto, alguns autores defendem que existe uma linha tênue que diferencia o marketing interno do endomarketing, conforme Kotler (1992):

"O conceito de Marketing exige que a empresa desenvolva tanto o Marketing Interno como o externo. Marketing Interno é a tarefa bem-sucedida de contratar, treinar e motivar funcionários capazes de servir bem aos clientes. Aliás, o Marketing Interno deve preceder o externo" (KOTLER, 1992 p.50).

Assim, Inkotte (2000) apresenta duas opções: o Endomarketing como um método estratégico opcional e o Marketing Interno, que é uma etapa precedente ao Marketing e possui caráter obrigatório. O Quadro 1 apresenta as principais diferenças identificadas por Inkotte (2000). 
Quadro 1 - Diferenças entre Marketing Interno e Endomarketing

\begin{tabular}{|l|l|}
\hline Marketing Interno & Endomarketing \\
\hline $\begin{array}{l}\text { Tem no cliente externo o seu mercado-alvo e, } \\
\text { a partir desta máxima, treina, motiva e adapta } \\
\text { seus funcionários para a consecução de seus } \\
\text { objetivos. }\end{array}$ & $\begin{array}{l}\text { Tem o cliente interno como um segmento } \\
\text { de mercado e adapta sua empresa para } \\
\text { motivar e conquistar seus funcionários. }\end{array}$ \\
\hline $\begin{array}{l}\text { Não há Marketing sem Marketing Interno } \\
\text { (pré-requisito). }\end{array}$ & $\begin{array}{l}\text { Forma opcional de gestão para as } \\
\text { empresas que adotam a administração de } \\
\text { Marketing. }\end{array}$ \\
\hline $\begin{array}{l}\text { A empresa confecciona seu produto, que é } \\
\text { ofertado ao mercado. }\end{array}$ & A empresa é o seu produto. \\
\hline
\end{tabular}

Fonte: Inkotte (2000).

Assim, pode-se concluir que existem diferentes linhas de pensamento com relação ao Marketing Interno e o Endomarketing, enquanto alguns autores consideram os conceitos como tendo o mesmo significado, outros encontram diferenças sutis entre eles. Considerando o exposto acima, este trabalho se adere ao conceito de endomarketing.

\section{PROCEDIMENTOS METODOLÓGICOS}

\section{ELABORAÇÃO E APLICAÇÃO DA PESQUISA}

Nessa fase, a pesquisa de clima foi adaptada com base na pesquisa de LUZ (2003), para poder ser aplicada no porte da empresa. Para tanto, as atividades a seguir foram realizadas:

E1 - Planejamento da Pesquisa: Nesta etapa realizou-se o planejamento das atividades, em termos de recursos e disponibilidades, bem como em termos de tempo. Foi subdividida em três etapas:

\section{E1.1: Objetivo da Pesquisa}

Foram determinados juntamente com os sócios da imobiliária os objetivos da pesquisa.

Os objetivos principais foram:

- Avaliar a satisfação dos funcionários com relação a empresa;

- Avaliar o como os funcionários enxergam a liderança;

- Descobrir os pontos que os funcionários consideram mais críticos dentro da empresa.

\section{E1.2: Definição da Técnica a ser usada}

Por questão de tempo de aplicação, foi escolhido desenvolver um questionário, pois é possível que todos os funcionários o respondam ao mesmo tempo, além de preservar a identidade dos colaboradores, fazendo com que as pessoas se sintam mais à vontade de dar sua verdadeira opinião sem ter medo de serem repreendidas. 


\section{E1.3: Abrangência da Pesquisa}

Como a empresa possui poucos funcionários, foi decidido na etapa E1.3 que a pesquisa seria realizada com todos os funcionários, totalizando 12 pessoas.

E2 - Construção do Questionário: Para a definição da etapa E2, o questionário foi adaptado a partir da pesquisa de clima construída pelo autor Luz (2003) em sua tese de mestrado, a qual possui aproximadamente 172 perguntas. O próprio autor sugere que o questionário seja reduzido, pois muitas perguntas acabam sendo repetidas, mudando somente a forma como foram escritas.

O número de perguntas não deve ser muito grande, uma vez que uma quantidade excessiva pode induzir o respondente a marcar qualquer resposta apenas para acabar logo o questionário.

Assim, foi feito um levantamento prévio das perguntas consideradas mais interessantes para serem feitas, levando em consideração as observações feitas pelos sócios da empresa e pelo próprio Luz (2003), por exemplo, o autor considera a pergunta: "Como você se imagina daqui a dois anos?", uma pergunta de extrema importância, dado que caso muitos funcionários respondam que gostariam de estar em outra empresa, esse resultado pode ser significativo para os donos da mesma.

Com o primeiro levantamento das questões, foi possível chegar a um total de 40 perguntas iniciais, com pelo menos uma pergunta de cada grupo apresentado no item 2.2.3 - Pesquisas de Clima Organizacional, além de dar prioridade às perguntas que possuíam respostas na escala de Likert, o que posteriormente facilitou a análise das mesmas. Todavia, devido a sua importância, foram adicionadas também questões com resposta de sim e não e com escalas de 1 a 10.

Com o questionário inicial pronto, foi feito um pré-teste, aplicado em 5 pessoas que não possuíam nenhum vínculo com a empresa, escolhidas de maneira aleatória, para poder saber se o questionário estava claro e intuitivo.

Enfim, o questionário final obteve um total de 31 perguntas, sendo 20 delas com respostas na escala Likert, 1 pergunta que classifica a área na qual o colaborador trabalha, 5 perguntas de sim e não, 4 perguntas de múltipla escolha e 1 pergunta aberta. Todas as perguntas são de caráter obrigatório, exceto a pergunta aberta. $O$ questionário final pode ser visto na íntegra no Apêndice $A$. Com este questionário, foi possível atender 15 dos 17 itens apresentados no Quadro 1 , os itens que não foram considerados são: Responsabilidade/Autonomia, Transporte casa/trabalho/casa, Nível sociocultural.

E3: Definição da Periodicidade: A etapa E3 é a última parte da elaboração da pesquisa de clima, na qual fica como sugestão ter uma periodicidade de aplicação do questionário não inferior a um ano, uma vez que alguns problemas encontrados a partir da pesquisa de clima podem demorar mais de um ano para serem resolvidos, além disso, algumas soluções podem requerer quantidades maiores de investimentos, que podem demorar a serem conseguidas, precisando assim de mais tempo. Fica a cargo dos sócios definirem esta periodicidade. 
E4: Aplicação da Pesquisa: Por questões de disponibilidade da empresa, a aplicação da pesquisa foi realizada no mês de Agosto/2015, na sede da empresa, em Joinville. Os funcionários colocaram seus questionários respondidos dentro de uma caixa, garantindo mais uma vez que a identidade das respostas ficasse anônima.

\section{ANÁLISE DOS RESULTADOS DA PESQUISA}

Foi utilizada a escala de Likert, que mede o nível de concordância das pessoas em uma afirmação (COSTA, 2011). Ela possui respostas que variam para cada item de acordo com o seu grau de intensidade (BADRI, 1995).

Para cada opção de resposta é conferido um número que irá refletir este grau de intensidade da mesma com relação à pergunta feita. Ou seja, as respostas possuem uma escala qualitativa e uma escala quantitativa, por exemplo: concordo totalmente (5), concordo (4), neutro (3), discordo (2) e discordo totalmente (1) (MATTAR, 2001).

A principal vantagem de utilizar a escala de Likert é a facilidade que a pessoa que está respondendo o questionário tem de mostrar o seu grau de concordância sobre a pergunta, fazendo com que o manuseio da escala seja fácil (COSTA, 2011).

Para realizar a análise da pesquisa de clima, as respostas de cada pergunta foram classificadas como respostas favoráveis, neutras e desfavoráveis.

Depois da classificação foi realizado o cálculo dos índices de favorabilidade por perguntas e por grupos, que corresponde a somatória dos pesos dados a cada resposta multiplicado pela frequência de respostas em cada alternativa, dividido pelo resultado máximo possível, ou seja, o número total de respostas vezes o maior peso, que corresponde a alternativa mais favorável (Perspectiva, 2016).

A fórmula 1 apresenta como o índice de favorabilidade é calculado.

$$
I F=\frac{\Sigma((\mathrm{P} 1 * \mathrm{~N} 1)+(\mathrm{P} 2 * \mathrm{~N} 2)+(\mathrm{P} 3 * \mathrm{~N} 3)+\ldots(\mathrm{Pn} * \mathrm{Nn}))}{(P 1 * T)}
$$

$$
\begin{aligned}
& \text { Onde: } \\
& \text { IF = índice de favorabilidade } \\
& \text { P1 = maior peso } \\
& \text { N1 = número de vezes que a resposta mais favorável foi respondida } \\
& \text { P2 = segundo maior peso } \\
& \text { N2 = número de vezes que a segunda resposta mais favorável foi respondida } \\
& \text { Pn = Peso dado a cada resposta } \\
& \text { Nn = Número de vezes que essa resposta foi dada } \\
& \text { T = Total de respostas obtidas }
\end{aligned}
$$


Este índice consegue mostrar que quanto maior o resultado obtido, mais próximo estará à resposta em questão de atingir o seu nível ideal.

Os pesos dados a cada resposta seguiram a escala Likert, no entanto, para que a maioria das perguntas, pudessem entrar no cálculo do IF, a escala foi adaptada para as perguntas nas quais as respostas eram: Sim, Não, Mais ou Menos/Alguma possibilidade.

As escalas usadas e a classificação entre Resposta Favorável, Resposta Neutra e Resposta Desfavorável estão apresentadas nas Tabelas 1, 2, 3 e 4 abaixo.

Tabela 1- Escala de Likert adaptada

\begin{tabular}{|l|c|l|}
\hline \multicolumn{1}{|c|}{ Resposta } & Peso dado à resposta & \multicolumn{1}{c|}{ Classificação } \\
\hline Muito Satisfeito & 5 & Resposta Favorável \\
\hline Satisfeito & 4 & Resposta Favorável \\
\hline Mais ou menos & 3 & Resposta Neutra \\
\hline Insatisfeito & 2 & Resposta Desfavorável \\
\hline Muito Insatisfeito & 1 & Resposta Desfavorável \\
\hline
\end{tabular}

Fonte: Autores (2017).

Tabela 2 - Escala de Likert adaptada

\begin{tabular}{|l|c|l|}
\hline \multicolumn{1}{|c|}{ Resposta } & Peso dado à resposta & \multicolumn{1}{c|}{ Classificação } \\
\hline Sempre & 4 & Resposta Favorável \\
\hline Quase sempre & 3 & Resposta Favorável \\
\hline Raramente & 2 & Resposta Neutra \\
\hline Nunca & 1 & Resposta Desfavorável \\
\hline Não tenho opinião & - & - \\
\hline
\end{tabular}

Fonte: Autores.

Na Tabela 2, a resposta "Não tenho opinião", ficou sem peso, pois ela representa os funcionários que não sabem como se sentem com relação a resposta ou preferem não se manifestar.

Tabela 3 - Escala de Likert adaptada

\begin{tabular}{|l|c|l|}
\hline \multicolumn{1}{|c|}{ Resposta } & Peso dado à resposta & \multicolumn{1}{c|}{ Classificação } \\
\hline Sim & 3 & Resposta Favorável \\
\hline Não & 1 & Resposta Desfavorável \\
\hline Mais ou Menos/ Alguma possibilidade & 2 & Resposta Neutra \\
\hline
\end{tabular}

Fonte: Autores (2017).

A pergunta "Numa escala de 1 a 10, como você classificaria a imagem da empresa perante os funcionários?" Também foi colocada na escala Likert conforme tabela 4. 
Tabela 4 - Escala de Likert adaptada

\begin{tabular}{|c|c|l|}
\hline Resposta & Peso dado à resposta & \multicolumn{1}{|c|}{ Classificação } \\
\hline 0 & 1 & Resposta Desfavorável \\
\hline 0 & 1 & Resposta Desfavorável \\
\hline 0 & 2 & Resposta Desfavorável \\
\hline 0 & 2 & Resposta Desfavorável \\
\hline 0 & 3 & Resposta Neutra \\
\hline 1 & 3 & Resposta Neutra \\
\hline 1 & 4 & Resposta Favorável \\
\hline 5 & 4 & Resposta Favorável \\
\hline 3 & 5 & Resposta Favorável \\
\hline 1 & 5 & Resposta Favorável \\
\hline
\end{tabular}

Fonte: Autores (2017).

Outro ponto a ser levantado é que houveram quatro perguntas que não puderam ser classificadas na escala Likert, devido as respostas serem mais abrangentes, estas são as perguntas: "Como você se imagina daqui a dois anos? ", "Indique as duas principais razões pelas quais você trabalha na empresa", "Indique os dois principais fatores que geram mais insatisfação no seu trabalho", "A empresa poderia melhorar se: ". Isso se torna um fator limitador da pesquisa de clima realizada, o que será feito para amenizar esta dificuldade será avaliar estas perguntas individualmente para ver quais melhorias podem surgir a partir dos seus resultados.

Visando facilitar a análise, foi feita uma média ponderada dos índices de favorabilidade separada por grupos, e a partir destes IF's, é possível calcular o índice potencial de melhoria, que indicará o porcentual que a cada grupo em questão tem para melhorar. Ele é calculado conforme apresentado na fórmula 2.

$$
I P M=100 \%-I F
$$

Onde:

IPM = índice potencial de melhoria

IF = índice de favorabilidade

O segundo cálculo feito para a análise dos resultados foi o IF global e o IPM global que são o resultado da média aritmética dos IF e IPM dos grupos.

Os grupos foram classificados em Classes de Favorabilidade, usando o IF como parâmetro, conforme apresentado na Tabela 5. 
Tabela 5 - Classes dos Índices de Favorabilidade

\begin{tabular}{|l|l|}
\hline \multicolumn{1}{|c|}{ Faixa de IF } & \multicolumn{1}{c|}{ Classe } \\
\hline Entre 86,68 e 100,00 & Muito Alta \\
\hline Entre 73,34 e 86,67 & Alta \\
\hline Entre 60,01 e 73,33 & Média Alta \\
\hline Entre 46,68 e 60,00 & Média Baixa \\
\hline Entre 33,34 e 46,67 & Baixa \\
\hline Entre 20,00 e 33,33 & Muito Baixa \\
\hline
\end{tabular}

Fonte: Adaptado de Relatório de Perspectiva (2016).

Por último, foi calculado através da média ponderada dos índices de favorabilidade de cada grupo, um IF Global e um IMP Global.

As perguntas foram divididas em 16 grupos para facilitar a análise, como mostra o Quadro 3. As questões com um * no final, são as que não puderam ser classificadas na escala de Likert.

Quadro 1 - Divisão das Perguntas

\begin{tabular}{|c|c|}
\hline Grupo & Perguntas \\
\hline $\begin{array}{l}\text { G1: Motivação } \\
\text { (recompensa, } \\
\text { promoção, } \\
\text { remuneração, } \\
\text { justiça)* }\end{array}$ & $\begin{array}{l}\text { O seu trabalho lhe dá um sentimento de realização profissional? } \\
\text { Você está satisfeito por trabalhar na empresa? } \\
\text { Existe reconhecimento pelos trabalhos bem-feitos pelos } \\
\text { funcionários? } \\
\text { Você se sente satisfeito em relação ao seu salário? } \\
\text { Indique os dois principais fatores que geram mais insatisfação no } \\
\text { seu trabalho. } \\
\text { Indique as duas principais razões pelas quais você trabalha na } \\
\text { empresa. }\end{array}$ \\
\hline $\begin{array}{l}\text { G2: Participação/ } \\
\text { Iniciativa/Integração }\end{array}$ & $\begin{array}{l}\text { A empresa é aberta a receber e reconhecer as opiniões e } \\
\text { contribuições de } \\
\text { Você tem liberdade para fazer o seu trabalho da forma como } \\
\text { considera melhor? }\end{array}$ \\
\hline G3: Liderança & $\begin{array}{l}\text { Você acha que os superiores são receptivos às críticas dos seus } \\
\text { subordinados? } \\
\text { Você considera justas as decisões tomadas pela diretoria em } \\
\text { relação aos funcionários da empresa? } \\
\text { Você tem uma ideia clara sobre o resultado que o seu superior } \\
\text { espera do seu trabalho? }\end{array}$ \\
\hline G4: Estrutura/Regras & $\begin{array}{lrrr}\begin{array}{l}\text { Seu superior imediato } \\
\text { interno/externo }\end{array} & \begin{array}{r}\text { trata a satisfação } \\
\text { como }\end{array} & \begin{array}{r}\text { cliente } \\
\text { prioridade }\end{array} \\
\text { máxima? } & & & \\
\end{array}$ \\
\hline G5: Treinamento & $\begin{array}{l}\text { O treinamento que você recebe o capacita a fazer bem o seu } \\
\text { trabalho? }\end{array}$ \\
\hline $\begin{array}{l}\text { G6: } \\
\text { Relacionamento/Coop } \\
\text { eração }\end{array}$ & 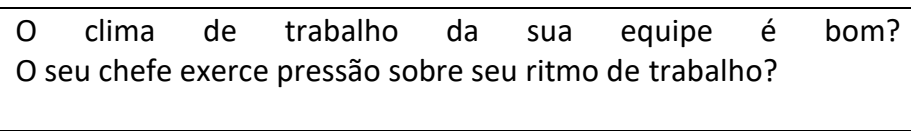 \\
\hline $\begin{array}{l}\text { G7: Cultura } \\
\text { organizacional }\end{array}$ & $\begin{array}{l}\text { O trabalho em equipe é incentivado pela empresa? } \\
\text { O compromisso da empresa com a qualidade dos seus produtos, } \\
\text { serviços e processos está visível no trabalho diário? }\end{array}$ \\
\hline $\begin{array}{l}\text { G8: } \\
\text { Identidade/Orgulho* }\end{array}$ & $\begin{array}{l}\text { A empresa costuma melhorar os produtos e serviços prestados } \\
\text { aos seus clientes? } \\
\text { A empresa atende prontamente às solicitações dos seus clientes? } \\
\text { Numa escala de } 1 \text { a } 10, \text { como você classificaria a imagem da } \\
\text { empresa perante } \quad \text { os } \\
\text { A empresa poderia melhorar se: }\end{array}$ \\
\hline
\end{tabular}




\begin{tabular}{|l|l|}
\hline $\begin{array}{l}\text { G9: Oportunidade de } \\
\text { crescimento/Incentivo } \\
\text { s profissionais }\end{array}$ & $\begin{array}{l}\text { Você vê possibilidade de crescimento de carreira, o curto ou } \\
\text { médio prazo, na empresa? }\end{array}$ \\
\hline $\begin{array}{l}\text { G10: Estabilidade no } \\
\text { emprego* }\end{array}$ & $\begin{array}{l}\text { Os funcionários do seu setor sentem-se seguros no emprego? } \\
\text { Como você se imagina daqui a dois anos? }\end{array}$ \\
\hline G11: Benefícios & $\begin{array}{l}\text { Os benefícios oferecidos pela empresa atendem às suas } \\
\text { necessidades? }\end{array}$ \\
\hline G12: Conflito & $\begin{array}{l}\text { Na sua equipe de trabalho, pontos de vista divergentes são } \\
\text { debatidos antes de se tomar uma decisão? }\end{array}$ \\
\hline G13: Comunicação & $\begin{array}{l}\text { A empresa normalmente cumpre as promessas feitas aos seus } \\
\text { funcionários? }\end{array}$ \\
\hline $\begin{array}{l}\text { G14: } \\
\text { Consideração/Prestígi } \\
\text { o/Tolerância }\end{array}$ & $\begin{array}{l}\text { As pessoas competentes são as que têm as melhores } \\
\text { oportunidades na empresa? }\end{array}$ \\
\hline $\begin{array}{l}\text { G15: Clareza } \\
\text { organizacional }\end{array}$ & $\begin{array}{l}\text { Você se considera bem informado sobre o que se passa na } \\
\text { empresa? }\end{array}$ \\
\hline $\begin{array}{l}\text { G16: Comentários } \\
\text { Que sugestões você daria para tornar a empresa um lugar melhor } \\
\text { para se trabalhar? * }\end{array}$ \\
\hline
\end{tabular}

Fonte: Autores (2017).

\section{ELABORAÇÃO DAS AÇÕES DE ENDOMARKETING}

Para a elaboração das ações de endomarketing, foi calculado o índice de favorabilidade e o índice potencial de melhoria de cada pergunta da pesquisa de clima organizacional e logo em seguida foram calculados estes índices para cada grupo no qual as perguntas estavam classificadas, a partir dos índices de cada grupo foram elencados os grupos com as menores notas. Para que a análise deles seja feita de forma aprofundada, cada pergunta pertencente aos grupos foi analisada de forma individual. Também foi feita uma entrevista não estruturada com os gestores para tentar esclarecer algumas questões pontuais que surgiram durante as análises.

\section{RESULTADOS}

O projeto descrito será realizado em uma empresa familiar do ramo imobiliário localizada em Joinville, que faz parte da Rede Morar, a empresa iniciou suas atividades outubro de 1976, sendo uma das pioneiras na implantação de loteamentos na cidade. Em 1998, após a morte do fundador da empresa, ela foi assumida pelos quatro filhos dele. Após a aplicação da pesquisa, foram obtidos os resultados apresentados nas Figuras a seguir, os quais demonstram resultados de cada grupo individualmente.

Foi feita uma análise de cada um dos grupos separadamente para poder compreender melhor seus resultados. Os grupos que possuem um ${ }^{*}$ são os grupos nos quais as perguntas que não puderam ser classificadas pela escala Likert estão inseridas. 
As Figuras 1 e 2 comparam o índice de favorabilidade e o índice potencial de melhoria entre os grupos.

Figura 1. Comparação do IF entre os grupos

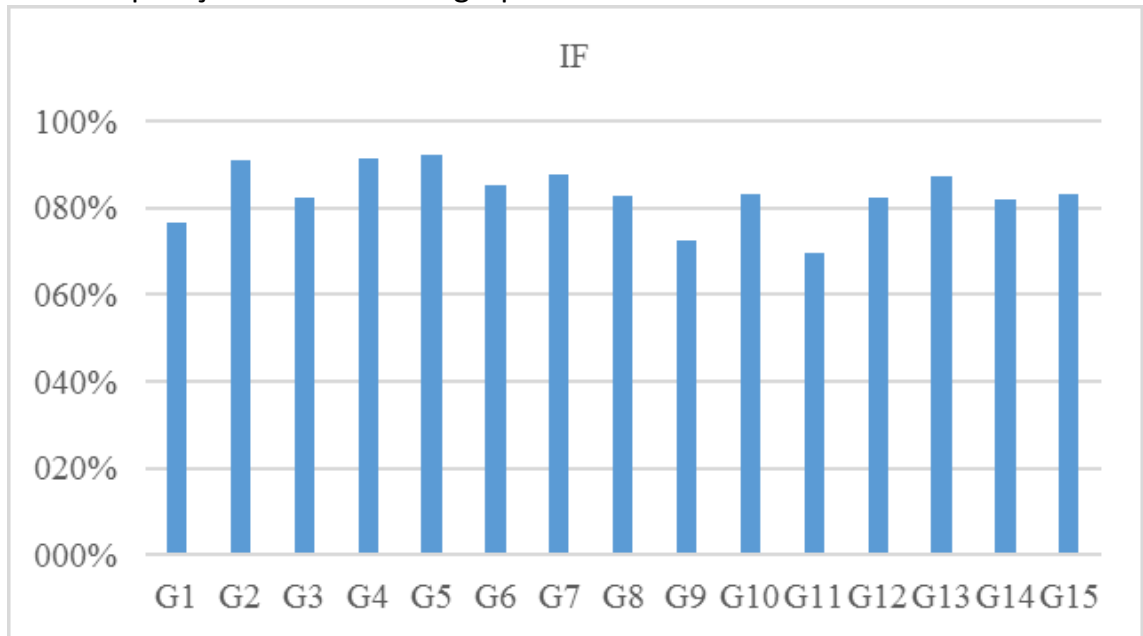

Fonte: Autores (2017)

Figura 2. Comparação do IPM entre os grupos

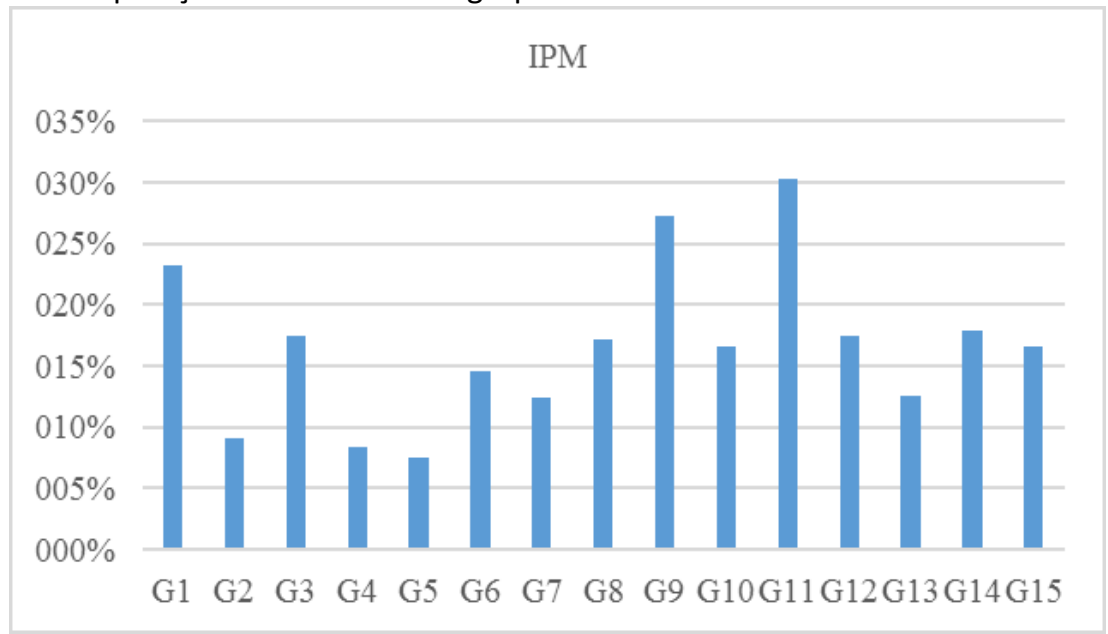

Fonte: Autores (2017)

As Figuras 1 e 2 mostram o IF e o IPM, o principal objetivo destes gráficos é salientar as diferenças entre os grupos, para indicar as principais ações a serem tomadas.

Por último, a Tabela 6, mostra um resumo dos resultados com o cálculo do IF e do IPM global e a classificação dos grupos de acordo com a Tabela 5 (Classes dos Índices de Favorabilidade).

Através do cálculo do índice de favorabilidade, foi possível elencar os sete grupos que obtiveram os menores índices. São eles:

G1: Motivação (recompensa, promoção, remuneração, justiça) *;

G3: Liderança;

G8: Identidade/orgulho; 
G9: Oportunidade de crescimento/Incentivos profissionais;

G11: Benefícios;

G12: Conflito;

G14: Consideração/Prestígio/Tolerância;

A classificação "Média Alta" foi a mais baixa dada a um dos grupos, logo, conclui-se que todos os grupos obtiveram um IF bom, sendo assim, estes sete grupos citados anteriormente são os grupos que possuem mais margem para serem trabalhados, mas não podemos dizer que obtiveram notas ruins.

Tabela 6. Resumo dos resultados obtidos com a pesquisa de clima

\begin{tabular}{|c|c|c|c|c|c|c|}
\hline Grupo & Respostas Favoráveis & Respostas Neutras & Respostas Desfavoráveis & Índice de Favorabilidade & Classe & Índice Potencial de Melhoria \\
\hline G1 & 36 & 9 & 1 & $76,74 \%$ & alta & $23,26 \%$ \\
\hline G2 & 22 & 0 & 0 & $90,91 \%$ & muito alta & $9,09 \%$ \\
\hline G3 & 32 & 1 & 0 & $82,58 \%$ & alta & $17,42 \%$ \\
\hline G4 & 12 & 0 & 0 & $91,67 \%$ & muito alta & $8,33 \%$ \\
\hline G5 & 10 & 0 & 0 & $92,50 \%$ & muito alta & $7,50 \%$ \\
\hline G6 & 18 & 3 & 2 & $85,48 \%$ & alta & $14,52 \%$ \\
\hline G7 & 19 & 1 & 0 & $87,63 \%$ & muito alta & $12,37 \%$ \\
\hline G8 & 31 & 3 & 0 & $82,78 \%$ & alta & $17,22 \%$ \\
\hline G9 & 3 & 7 & 1 & $72,73 \%$ & média alta & $27,27 \%$ \\
\hline G10 & 6 & 6 & 0 & $83,33 \%$ & alta & $16,67 \%$ \\
\hline G11 & 3 & 6 & 2 & $69,70 \%$ & média alta & $30,30 \%$ \\
\hline G12 & 9 & 1 & 0 & $82,50 \%$ & alta & $17,50 \%$ \\
\hline G13 & 10 & 0 & 0 & $87,50 \%$ & muito alta & $12,50 \%$ \\
\hline G14 & 7 & 0 & 0 & $82,14 \%$ & alta & $17,86 \%$ \\
\hline G15 & 7 & 4 & 1 & $83,33 \%$ & alta & $16,67 \%$ \\
\hline IF Global & $83 \%$ & Alta & & & & \\
\hline IPM Global & $17 \%$ & & & & & \\
\hline
\end{tabular}

\section{SÍNTESE DOS RESULTADOS}

Com base nas análises feitas e nas respostas obtidas através da entrevista com os sócios, foi possível identificar dois macros grupos, o M1, que é composto por: Benefícios, Consideração/Prestígio/Tolerância, Oportunidade de crescimento/Incentivos profissionais e Motivação (recompensa, promoção, remuneração, justiça). E o grupo M2, composto por: Conflito, Identidade/Orgulho e Liderança.

Para o M1, foi visto que existe uma falta com relação aos benefícios, o salário e o crescimento dentro da empresa e para trabalharmos estes pontos será proposto um plano de carreiras.

O salário foi um ponto importante que se destacou nas respostas da pesquisa de clima, porém, de acordo com a teoria apresentada, ele possui um pequeno impacto no desempenho em longo prazo da satisfação dos funcionários, desta forma, o intuito será não mexer diretamente no salário, mas trabalhar nele de uma forma indireta através do plano de carreiras que será proposto. No M2, existe uma falta de comunicação clara entre os líderes e os colaboradores, desta forma será proposta a caixa de sugestões, pois esta servir como um canal de comunicação entre ambas às partes.

A Figura 3 apresenta a relação dos resultados encontrados com as ações de endomarketing propostas.

Figura 3. Relação dos resultados da pesquisa de clima com as ações de endomarketing 


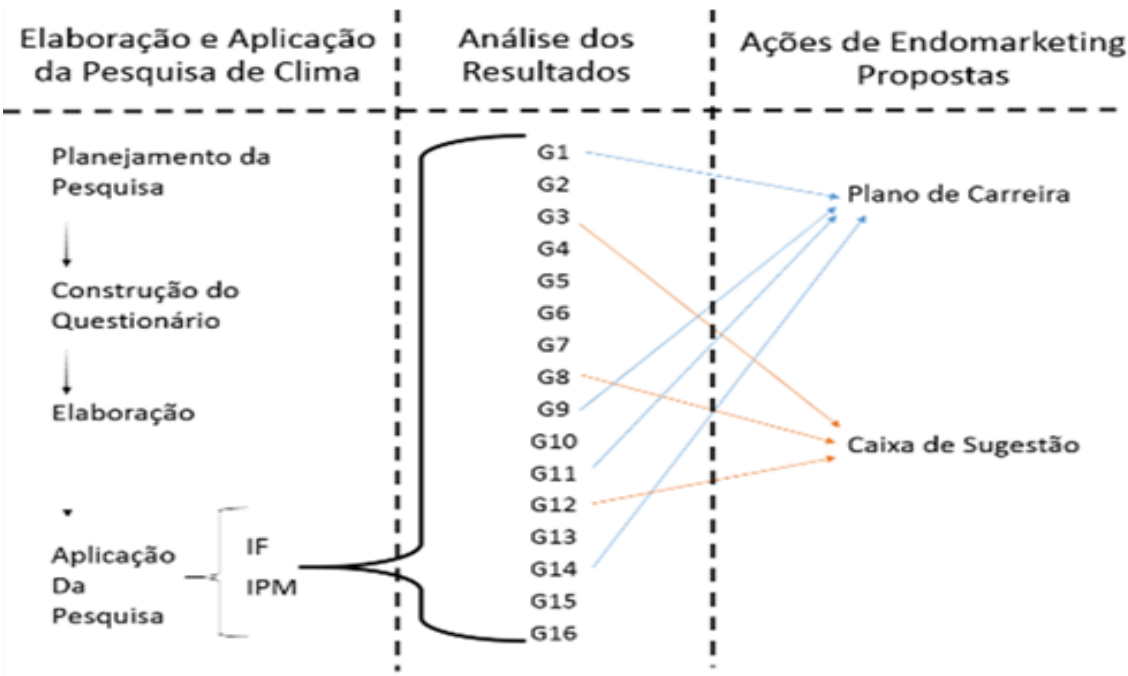

\section{ATIVIDADES PROPOSTAS DE ENDOMARKETING}

A partir das análises, foi possível desenvolver estratégias de endomarketing que ajudarão a empresa a melhorar esses grupos com os piores índices. $O$ intuito desses encaminhamentos é que eles tenham um baixo custo de implantação, já que atualmente a empresa não possui insumos suficientes para realizar um alto investimento, são eles: Plano de Carreiras e Caixa de Sugestões.

\section{APRIMORAMENTO DO PLANO DE CARREIRA}

O plano de carreira é uma das ferramentas do endomarketing, pois ele mostra aos colaboradores quais são suas oportunidades de crescimento dentro da empresa. A motivação de um funcionário deve estar conectada a cultura da organização, o que faz com que esta ferramenta seja uma essencial na cultura da mesma.

Este plano aprimorado ajudará a empresa a reter por mais tempo seus funcionários, fará com que eles fiquem motivados a melhorar suas vendas e alcançar suas metas, além de poderem ter uma oportunidade de serem reconhecidos pelo seu trabalho. Com a possibilidade de crescimento e reconhecimento profissional dentro da empresa, o clima empresarial apresentará melhoras.

O plano de carreira irá atuar pontualmente no grupo $M 1$, que é composto por: Benefícios, Consideração/Prestígio/Tolerância, Oportunidade de crescimento/Incentivos profissionais e Motivação (recompensa, promoção, remuneração, justiça).

\section{Situação Atual}

Hoje a empresa possui poucas ferramentas de endomarketing implementadas, uma delas é o evento que ocorre mensalmente para comemorar o aniversário de todos os funcionários que nasceram no respectivo mês. $O$ evento ocorre toda segunda quinta-feira do mês e é pago pela empresa. 
Além do evento de aniversário, a empresa possui um plano de carreiras informal, pois não existe uma conversa formal sobre a possibilidade e crescimento dentro da empresa, e não é apresentado nenhum plano para o funcionário neste sentido.

A empresa é dividida em três áreas: Locação, vendas e administrativo. Na locação, são 2 funcionárias que cuidam dos aluguéis e uma gerente de locação. $\mathrm{Na}$ área de vendas, são 6 corretores e uma gerente de vendas, por fim, na administração, são duas pessoas e o gerente desta área é um dos sócios.

O pré-requisito para ser um corretor de imóveis é ter feito o curso de Técnico em Transações Imobiliárias, fornecido pelo $\mathrm{CRECl}$, que é o Conselho Regional de Corretores de Imóveis de Santa Catarina, caso o candidato tenha feito o curso em outro estado, ele deve primeiro regularizar sua situação no CRECI para depois poder começar a trabalhar como corretor de imóveis.

O plano de carreira seria um funcionário da locação ou da venda conseguir virar gerente desta área e, para a administração, não existe a possibilidade de se tornar gerente, pois quem ocupa o cargo é um dos sócios.

Os donos da empresa relataram que a mesma trabalha com o sistema de recompensas através de comissões de vendas e de locações, mesmo assim, os funcionários se mostram pouco motivados, pois quando conseguem uma venda no mês, não se esforçam para continuar vendendo.

Quadro 2 - Situação Atual do Plano de Carreira no Setor de Vendas

\begin{tabular}{|c|c|}
\hline \multicolumn{2}{|c|}{ Sistema de Cargos, Metas e Remuneração atual } \\
\hline \multicolumn{2}{|l|}{ Setor: Vendas } \\
\hline Cargo: Vendas & Cargo: Gerente de Vendas \\
\hline $\begin{array}{l}\text { Salário: } 1,5 \% \text { sobre o valor do imóvel } \\
\text { vendido }\end{array}$ & $\begin{array}{l}\text { Salário: } \mathrm{R} \$ 3.000,00+6 \% \text { sobre as comissões } \\
\text { dos seus subordinados }\end{array}$ \\
\hline \multicolumn{2}{|c|}{ Metas por funcionário } \\
\hline Vender 1 imóvel por mês & $\begin{array}{l}\text { Fazer todos os vendedores venderem um } \\
\text { imóvel por mês }\end{array}$ \\
\hline Principais Atribuições & Principais Atribuições \\
\hline 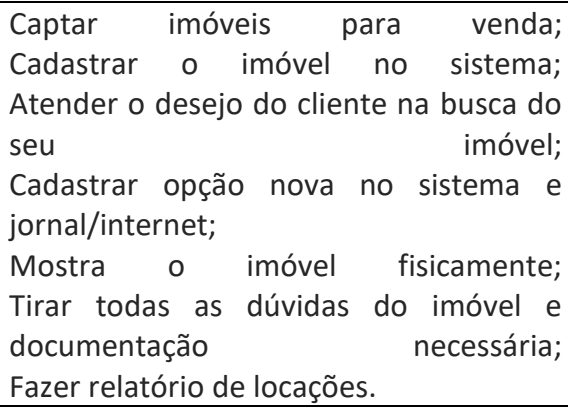 & 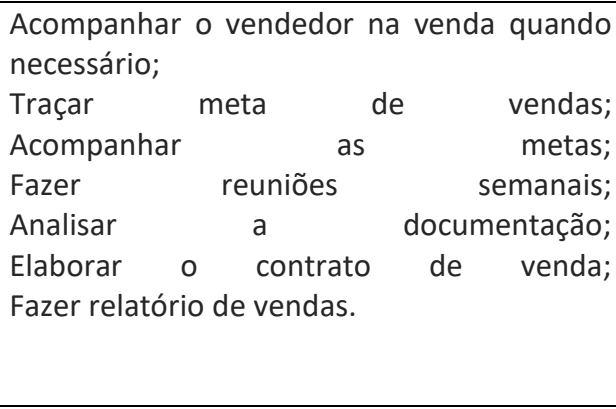 \\
\hline \multicolumn{2}{|c|}{ Pré-requisito mínimo para ocupação do cargo } \\
\hline Curso CRECl & Experiência comprovada \\
\hline
\end{tabular}

Fonte: Autores (2017).

A empresa possui metas para os setores de locação e de vendas, são elas:

- Vendas: Cada corretor deve vender no mínimo 1 imóvel por mês;

- Locação: Cada funcionário deve locar no mínimo 3 imóveis por mês. 
- A área administrativa não possui metas.

No caso da venda de um imóvel, a imobiliária cobra como taxa do proprietário $6 \%$ do valor da venda, dessa porcentagem, 1,5\% fica para quem captou o imóvel e 1,5\% fica para o corretor que o vendeu. O Quadro 4 apresenta os detalhes dos cargos, metas e remuneração deste setor.

\section{Situação Proposta}

\section{Plano de carreira com metas}

Essa estratégia visa contemplar e melhorar diretamente o grupo M1, buscando proporcionar uma expectativa mais real de que é possível crescer dentro da empresa, quais são os critérios para que isso aconteça e as metas, que quando alcançadas, irão oferecer alguns benefícios a mais para os funcionários. $O$ Quadro 5 apresenta a proposta de plano de carreiras e metas, a remuneração fixa não foi modificada.

Quadro 3. Plano de Carreira de Vendas

\begin{tabular}{|c|c|c|}
\hline \multicolumn{3}{|c|}{ Sistema de Cargos, Metas e Remuneração atual } \\
\hline \multicolumn{3}{|l|}{ Setor: Vendas } \\
\hline Cargo: Vendedor Júnior & Cargo: Vendedor Sênior & Cargo: Gerente de Vendas \\
\hline $\begin{array}{l}\text { Salário: } \text { Baseado nas } \\
\text { comissões }\end{array}$ & $\begin{array}{l}\text { Salário: Baseado nas } \\
\text { comissões }\end{array}$ & $\begin{array}{l}\text { Salário: } \mathrm{R} \$ 3.000,00+6 \% \\
\text { sobre as comissões dos seus } \\
\text { subordinados }\end{array}$ \\
\hline \multicolumn{3}{|c|}{ Metas por Funcionário } \\
\hline $\begin{array}{lrrr}\text { Meta 1: } & \text { vender } & \mathrm{R} \\
\text { 190.000,00: } & 1,3 \% & \text { de } \\
\text { comissão } & & \\
\text { meta 2: } & \text { vender } & \mathrm{R} \$ \\
\begin{array}{l}\text { 400.000,00: } \\
\text { comissão }\end{array} & 1,4 \% & \text { de } \\
\text { meta 3: } & \text { vender } & \mathrm{R} \$ \\
\begin{array}{l}\text { 900.000,00: } \\
\text { comissão }\end{array} & 1,5 \% & \text { de } \\
& & \end{array}$ & 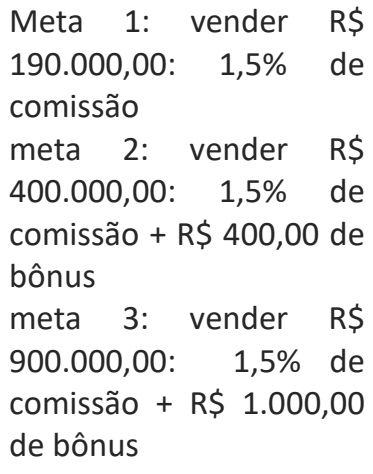 & Sen \\
\hline Principais Atribuições & Principais Atribuições & Principais Atribuições \\
\hline $\begin{array}{l}\text { Captar imóveis para } \\
\text { venda; } \\
\text { Cadastrar o imóvel no } \\
\text { sistema; } \\
\text { Atender o desejo do } \\
\text { cliente na busca do seu } \\
\text { imóvel; } \\
\text { Cadastrar opção nova no } \\
\text { sistema e jornal/internet; } \\
\text { Mostra o imóvel } \\
\text { fisicamente; } \\
\text { Tirar todas as dúvidas do } \\
\text { imóvel e documentação }\end{array}$ & $\begin{array}{l}\text { Captar imóveis para } \\
\text { venda; } \\
\text { Cadastrar o imóvel no } \\
\text { sistema; } \\
\text { Atender o desejo do } \\
\text { cliente na busca do seu } \\
\text { imóvel; } \\
\text { Cadastrar opção nova no } \\
\text { sistema } \\
\text { jornal/internet; } \\
\text { Mostra o imóvel } \\
\text { fisicamente; } \\
\text { Tirar todas as dúvidas do }\end{array}$ & $\begin{array}{l}\text { Acompanhar o vendedor na } \\
\text { venda quando necessário; } \\
\text { Acompanhar as metas; } \\
\text { Fazer reuniões semanais; } \\
\text { Analisar a documentação; } \\
\text { Elaborar o contrato de } \\
\text { venda; } \\
\text { Fazer relatório de vendas. }\end{array}$ \\
\hline
\end{tabular}




\begin{tabular}{|c|c|c|}
\hline $\begin{array}{l}\text { necessária; } \\
\text { Fazer relatório de } \\
\text { locações. }\end{array}$ & $\begin{array}{l}\text { imóvel e documentação } \\
\text { necessária; } \\
\text { Fazer relatório de } \\
\text { locações. }\end{array}$ & \\
\hline \multicolumn{3}{|c|}{ Pré-requisito mínimo para ocupação do cargo } \\
\hline Curso CRECl & $\begin{array}{l}\text { Ter vendido nos últimos } \\
3 \text { meses um valor de } R \$ \\
600.000,00\end{array}$ & $\begin{array}{l}\text { Ter no mínimo } 1 \text { ano de } \\
\text { empresa na área de vendas } \\
\text { e experiência comprovada } \\
\text { na área de gestão de } \\
\text { pessoas }\end{array}$ \\
\hline
\end{tabular}

Fonte: Autores (2017).

No Quadro 5, foi adicionado um nível intermediário, para criar uma escala maior de crescimento dentro da empresa. Também foram adicionados novos prérequisitos para subir de nível, visando incentivar ainda mais os corretores de imóveis a cumprirem suas metas e permanecerem na empresa por mais tempo. Como visto anteriormente, as metas que a empresa propôs para os seus colaboradores no setor de vendas são baseadas em números de imóveis vendidos por mês.

A nova proposta foi baseada em faturamento, pois, por exemplo, um funcionário pode vender dois apartamentos e outro vender apenas um, mas os valores dos primeiros somados seriam equivalentes ao valor do imóvel vendido pelo segundo corretor, nesse caso, se a meta for por número de imóveis, a empresa identificaria o primeiro vendedor como melhor, por ter feito o dobro do que o primeiro, mas se a meta for medida por retorno financeiro que essas vendas trouxeram para a imobiliária, ambos os corretores estariam no mesmo patamar. A meta por faturamento foi baseada na média de faturamento por imóvel da empresa, usando o histórico dos meses de janeiro a agosto de 2015, resultando em um valor médio de $\mathrm{R} \$ 195.600,00$ por imóvel.

Para o Vendedor Sênior, foi colocado um bônus extra de R\$ 400,00 e um de $R \$ 1.000,00$ reais para as metas 2 e 3 respectivamente, este valor foi calculado dentro da viabilidade da imobiliária, que seria aproximadamente $0,1 \%$ a mais na comissão, porém foi preferido pelos sócios colocar um valor fixo de bônus ao invés de um valor variável, pois caso seja vendido um imóvel de $R \$ 800.000,00$, o custo que seria de $\mathrm{R} \$ 12.800,00$ (1,6\%) fica $\mathrm{R} \$ 12.400,00$ (1,5\% + bônus). 0 cálculo das metas deve ser refeito todos os meses pelos sócios da imobiliária, para que ela não fique defasada.

Também foram adicionados os requisitos para subir de cargo, assim os colaboradores ficam cientes do que precisam fazer.

O caso das metas do gerente de vendas é o mesmo que o gerente de locações, o ganho será maior de acordo com as vendas dos subordinados, porém ele não ganha bônus, pois já tem um salário fixo como vantagem.

Acredita-se que esse plano proposto servirá de incentivo para que os funcionários procurem trabalhar com mais afinco, no entanto, isso só será comprovado depois da aplicação efetiva dessa estratégia.

Implementação 
Para a implementação do Plano de Carreiras, fica como sugestão iniciar primeiramente com uma conversa com todos os funcionários para apresentar o novo plano de carreiras, nesta conversa, todas as dúvidas devem ser esclarecidas e as opiniões dos funcionários também devem ser levadas em consideração, o que pode alterar alguns detalhes do plano proposto, caso as opiniões sejam relevantes.

Para o setor de Vendas, eles começarão no cargo de Vendedor Júnior, mas com a comissão de $1,5 \%$, que é a praticada atualmente, novamente, isso acontecerá apenas para os atuais funcionários com o intuito de não gerar um clima ruim na empresa, as metas permanecem as mesmas do cargo Vendedor Júnior e quando eles as alcançarem as mesmas, poderão subir para Vendedor Sênior. Os novos corretores que forem contratados, entrarão para o plano de carreiras conforme a Quadro 5.

\section{Ações de comunicação para o plano de carreiras}

Estas ações de comunicação têm como objetivo facilitar a implementação e manutenção do Plano de Carreira.

Fica como sugestão:

Visualização: Colocar as metas e o plano de carreiras à vista para que todos os funcionários vejam ajudará a manter os esforços concentrados nas metas criadas pela empresa e também servirá como um lembrete para os colaboradores do que eles precisam fazer para poder mudar de cargo ou ganhar mais bônus. A empresa possui uma área em comum, na qual apenas os funcionários podem circular, a sugestão é que o quadro de metas e o plano de carreira sejam colocados nesta área. $\mathrm{O}$ quadro de metas deverá ser atualizado semanalmente ou a cada quinze dias e deverá conter as metas em grupo e as metas individuais.

Holerite: Quando os funcionários receberem o seu holerite, poderia vir junto com ele uma folha mostrando as metas individuais do funcionário e se ele conseguiu atingi-las ou não.

Conversas em grupo: Reunião sobre metas de grupo a cada dois meses, com o intuito de motivar a equipe e também ouvir o que eles têm a dizer.

Conversas individuais: A cada dois meses, intercalar com as conversas em grupos, fazer uma reunião individual com cada funcionário. Como são doze funcionários no total e quatro sócios, cada sócio poderia conversar com três funcionários, assim não onera nenhum deles. Essas conversas sobre as metas também darão a oportunidade aos sócios de entenderem melhor o que está acontecendo com cada colaborador individualmente.

\section{CAIXA DE SUGESTÕES}

A caixa de sugestões irá proporcionar aos funcionários uma oportunidade de manifestar suas opiniões e, em contrapartida, os seus líderes deverão escutá-las, debatê-las com os funcionários e dar um retorno sobre o que será feito com a opinião dada, além de recompensar as boas ideias, fazendo com que exista uma maior participação e colaboração dos colaboradores, trazendo o sentimento de que a empresa pode ser construída e melhorada por todos. Esta ferramenta irá 
trazer melhorias para o grupo M2, composto por: Conflito, Identidade/Orgulho e Liderança.

\section{Situação Atual}

Hoje, a imobiliária não possui nenhuma ferramenta que facilite a comunicação entre os funcionários, de acordo com os sócios, as sugestões acontecem verbalmente, mas não existe um incentivo claro para que elas aconteçam.

\section{Situação Proposta}

A caixa de sugestões visa abrir uma oportunidade para os funcionários darem suas opiniões sobre os problemas e processos que ocorrem na empresa, além de poderem sugerir novas ideias.

Essa estratégia visa melhorar o grupo M2, para entender melhor o resultado do grupo Conflito, foi feita uma entrevista com a gestora. De acordo com ela, é tentado ao máximo ouvir os colaboradores, mas muitas vezes as decisões que são tomadas vão em contra a opinião dos mesmos, pois os gestores pensam primeiro no bem da imobiliária como um todo.

Dessa forma, o intuito da caixa de sugestões é de propor temas quinzenais para que a equipe possa dar sugestões mais direcionadas sobre os problemas que a imobiliária considerar mais críticos no momento, depois que as sugestões forem dadas, os sócios da empresa irão dar um retorno sobre as sugestões e abrir para novas discussões caso seja necessário. É de extrema importância que estes temas existam, pois eles irão direcionar as ideias para as maiores necessidades da imobiliária no momento. As melhores ideias podem ser premiadas com jantares ou finais de semana em algum hotel para o funcionário. Dessa forma, os colaboradores serão realmente ouvidos e verão que suas opiniões possuem valor dentro da empresa.

Um possível risco é de essa caixa se tornar um mural de reclamações, no qual os colaboradores apenas reclamam, mas não sugerem nada. Para evitar que isso aconteça, deve ser estruturado um formulário de preenchimento padrão, que contenha pelo menos o campo Problema e o campo Solução e deixar claro que o formulário só será levado em consideração caso estes campos estejam devidamente preenchidos.

A caixa de sugestões não precisa ser física, fica como sugestão fazê-la online, isso fará com que fique mais fácil dar as sugestões, estimulando ainda mais os funcionários. Existem algumas ferramentas online de caixa de sugestões que trazem ainda a opção de enquanto o prazo para as sugestões não tiver acabado, os funcionários podem comentar nas ideias uns dos outros, fomentando a melhoria das mesmas.

\section{Ações de comunicação para a caixa de sugestões}

Para garantir que os funcionários participem, serão mandados e-mails quinzenalmente falando sobre o tema em questão e pedindo que os eles deem 
suas sugestões e opiniões através da caixa que ficará em um lugar de fácil acesso para todos ou de forma online.

Alguns dias antes de acabar o período de sugestões para o tema dado, será mandado um novo e-mail avisando que o prazo está acabando e reforçando que a opinião de todos é muito importante.

Ao verem as sugestões, todas elas devem ser avaliadas e respondidas, caso a sugestão seja aceita ou não, o motivo deve ser exposto. A comunicação deve ser clara e ter bons argumentos, caso o contrário, isso pode desestimular os colaboradores a darem sua opinião, além disso, a premiação prometida a melhor ideia deve ser cumprida para garantir o incentivo.

\section{CONSIDERAÇÕES FINAIS}

O presente trabalho procurou desenvolver ações de endomarketing voltadas para pequenas imobiliárias, assim, foi desenvolvido um questionário de clima organizacional com base no modelo do autor Luz (2003), que é um modelo mais abrangente comparado aos outros da literatura. Contudo, este não foi idealizado para pequenas empresas, sendo necessário adaptá-lo. Dessa forma, chegou-se a um questionário com 31 perguntas, os resultados obtidos através deste instrumento foram adequados e de grande ajuda, pois permitiram medir o clima organizacional da empresa.

A pesquisa de clima teve como objetivo entender como os colaboradores enxergam a empresa e o seu trabalho, além de proporcionar a eles a chance de dar a sua opinião sobre o que eles gostariam que fosse melhorado, trazendo o benefício de ter o sentimento de que a opinião deles é importante e também de construir um retrato do clima organizacional atual da empresa. A pesquisa aplicada não mediu os fatores externos à empresa que também podem afetar o desempenho e a motivação dos funcionários, como por exemplo, os problemas familiares.

Com o diagnóstico encontrado a partir do questionário de clima organizacional, do índice de favorabilidade e do índice potencial de melhoria, foram identificados os fatores mais críticos dentro da empresa que poderiam ser trabalhados através de ações de endomarketing, os índices revelaram a prioridade de cada fator, sendo possível criar uma escala de prioridade e trabalhar primeiramente os piores fatores da empresa.

Considerando a priorização encontrada, foram identificadas duas grandes ações que conseguiam abordar vários grupos de itens, sendo elas o plano de carreiras e a caixa de sugestões. A primeira foi sugerida para que se conseguisse oferecer um novo benefício aos funcionários, melhorar a perspectiva deles com relação a seu crescimento e desenvolvimento dentro da imobiliária, assim como aumentar as oportunidades de ganhos dos colaboradores, dando a eles uma motivação maior para trabalhar e permanecer por mais tempo na empresa. A segunda ação foi voltada para a comunicação e resolução dos conflitos entre a liderança da empresa e seus subordinados, dando a ambas as partes um canal no qual eles poderão pedir e receber sugestões que possam melhorar a empresa e a motivação de todos dentro dela. 
Para ambas as ações foram sugeridas formas de implementação, que irão facilitar a adesão delas por todos da empresa. Observa-se que quando forem implementadas pela empresa, podem precisar de algumas alterações.

A pesquisa de clima foi a principal responsável para que estas duas ferramentas pudessem ser encontradas, pois ela ajudou a identificar os problemas mais atenuantes dentro da imobiliária, no entanto, usar apenas a pesquisa não é o suficiente, pois precisamos criar ações e implementa-las de forma corretiva e preventiva, para que o problema não se torne maior no futuro. Neste momento, o endomarketing usado foi desenvolvido para melhorar a motivação dos funcionários, sendo de extrema importância, pois ele ajudará a melhorar os indicadores previamente identificados como negativos pela pesquisa de clima. 


\title{
Climate surveys and internal marketing in SMES
}

\begin{abstract}
The objective of this article is to develop an endomarketing - internal marketing - strategy for small companies in the real state industry. The research is characterized as exploratory-descriptive and action research, using an adapted survey from the organizational climate model by Luz (2003). The results obtained helped the company in measuring its organizational climate. A favorability index and a improvement potential index were then constructed in order to assess the key issues at hand. In this sense, the company was able to prioritize two specific actions: a career plan and a suggestions box. Endomarketing - or internal marketing - helped, as well, in focusing on the low performing indicators and on improving the employee motivation, as outcomes of the organizational climate survey.
\end{abstract}

KEYWORDS: Organizational climate. Small companies. Endomarketing. Internal marketing. 


\section{REFERÊNCIAS}

AZEDO, S. Endomarketing cresce nas corporações. Gazeta Mercantil, [S.I.: s.n.], 2004.

BADRI, M. A.; DONALD, D.; DONNA, D. A study of measuring the critical factors of quality management. International Journal of Quality \& Reliability Management, v. 12, n. 2, p. 36-53, 1995. crossref

BEKIN, S. F. Conversando sobre Endomarketing. São Paulo: Makron Books, 1993.

BEDANI, M. Clima organizacional: investigação e diagnóstico: estudo de caso em agência de viagens e turismo. Psicologia para América Latina. v.1 n. 7 ago. 2006.

BISPO, C. A. F. Um novo modelo de pesquisa de clima organizacional. EESC - USP. Produção v.16, n.2, p. 258-273, Maio/Agosto 2006. crossref

BRUM, A.M. Endomarketing: como estratégia de gestão. 3 ed. Porto Alegre: L\&PM, 2005.

BRUM, A. M. Endomarketing de A a Z: como alinhar o pensamento das pessoas à estratégia da empresa. São Paulo: Integrare Editora, 2010.

CHIAVENATO, I. Administração de recursos humanos: fundamentos básicos. 6 . ed. São Paulo: Atlas, 2006.

COSTA, F. J. Mensuração e desenvolvimento de escalas: aplicações em administração. Rio de Janeiro: Ciência Moderna, 2011.

FREIRE, P. Pedagogia da Esperança: um reencontro com a Pedagogia do Oprimido. Rio de Janeiro: Paz e Terra. 16a ed. 2009.

INKOTTE, A. Endomarketing: elementos para a construção de um marco teórico. 2000. Dissertação (Mestrado em Engenharia de Produção) - Centro Tecnológico, Universidade Federal de Santa Catarina, Florianópolis.

KOTLER, P. Administração de Marketing: Análise Planejamento e Controle. São Paulo: Atlas, 1992.

KUNSCH, M. M. K. Planejamento de relações públicas na comunicação integrada. São Paulo: Summus, 2003. 
LACOMBE, F. J. M. Recursos humanos: princípios e tendências. São Paulo: Saraiva, 2005.

LITWIN, G.H. STRINGER R. A. Motivation and organizational climate. Cambridge: Harvard University Press, 1968.

LUZ, J. P. da. Metodologia para análise de clima organizacional: um estudo de caso para o Banco do Estado de Santa Catarina. Florianópolis: UFSC, 2001. Dissertação (Programa de Pós-Graduação em Engenharia de Produção), Universidade Federal de Santa Catarina, 2001.

LUZ, M. L. S.; KACHBA, Y. R.; BARBOSA, A. S.; OLIVEIRA, K. F.; VIEIRA, A. M. Pesquisa de clima organizacional: influência da qualidade de vida no trabalho. In: Anais do XXVII Encontro Nacional de Engenharia de Produção. Anais... Foz do Iguaçu, 2007.

LUZ, R. Gestão do clima organizacional. Rio de Janeiro: Qualitymark, 2003.

LUZ, R.S. Gestão do clima organizacional. 3. ed. Rio de Janeiro: Quality, 2007.

MATTAR, F. N. Pesquisa de marketing. Edição Compacta. 3.ed. São Paulo: Atlas, 2001.

MORAN, E. T.; VOLKWEIN, J. F. The cultural approach to the formation of organizational climate. Human Relations, v.45, n.1, 1992. crossref

PERSPECTIVA CONSULTORES. Pesquisa de Clima Organizacional. Disponível em: http://www.perspect.com.br/site/files/downloads/relatorio_pesquisa_individual. pdf. Acesso em: 08/03/2016.

SBRAGIA, R. Um estudo empírico sobre clima organizacional em instituições de pesquisa. Revista de Administração, v. 18, n. 2, p. 30-39, 1983.

SILVA, R. C. Clima organizacional: definições, relação com a cultura organizacional e pesquisa de clima. Monografia, Faculdade de Ciências da Saúde, Centro Universitário de Brasília, Brasília. 2001.

STONER, J. A. F; FREEMAN, R. E. Administração. 5. ed. Rio de Janeiro: LTC, 1999. 
TAMOYO, A., PASCHOAL, T. A relação da motivação para o trabalho com as metas do trabalhador. Revista de Administração Contemporânea, v. 7, n.4. Curitiba, out/dec 2003.

Recebido: 09 mar. 2017

Aprovado: 27 out. 2017

DOI: 10.3895/gi.v13n3.5663

Como citar:

ABREU, B. W.; VAZ, C. R.; MALDONADO, M. U. Pesquisa de clima e endomarketing para pequenas empresas. R. Gest. Industr., Ponta Grossa, v. 13, n. 3, p. 160-184, set./nov. 2017. Disponível em:

<https://periodicos.utfpr.edu.br/rgi>. Acesso em: XXX.

Correspondência:

Barbara Welter de Abreu

Campus-UFSC s/n, Bairro Trindade, Florianópolis, Santa Catarina, Brasil.

Direito autoral: Este artigo está licenciado sob os termos da Licença Creative Commons-Atribuição 4.0

Internacional.

\section{(c) (1)}

